\title{
ERRATA
}

\section{Binding of Cycloheximide to Ribosomes from Wild-Type and Mutant Strains of Saccharomyces cerevisiae}

\author{
WALTER STÖCKLEIN AND WOLFGANG PIEPERSBERG
}

Lehrstuhl für Mikrobiologie der Universität München, Munich, West Germany

Vol. 18, no. 6, p. 863, Abstract, line 10: "3.5 $\times 10^{-7} \mathrm{M}^{-1}$ " should read " $3.5 \times 10^{7} \mathrm{M}^{-1}$."

P. 864, column 1, line 13: Reference "(18)" should be "(8)."

\section{Bactericidal Activity of Cerumen}

TUU-JYI CHAI AND TOBY C. CHAI

Laboratory of Biochemistry and Metabolism, National Institute of Arthritis, Metabolism and Digestive Diseases, Bethesda, Maryland 20205

Vol. 18, no. 4, p. 640, column 1: Lines 3 and 4, which read "test cultures was dependent upon the concentrations of cerumen used. Perhaps a concentration," should follow line 34 .

\section{Susceptibility of Eikenella corrodens to Newer Beta-Lactam Antibiotics}

ELLIE J. C. GOLDSTEIN, MYLES E. GOMBERT, AND EMMANUEL O. AGYARE

Infectious Diseases Division, SUNY-Downstate Medical Center, Brooklyn, New York 11203

Vol. 18, no. 5 , p. 832 , column 2, line 25: Add "It is known that bacampicillin is converted to an active agent, ampicillin, in the presence of blood. Our use of Mueller-Hinton agar supplemented with $5 \%$ sheep blood may have caused this conversion in our test system."

P. 833, Table 1, column 3, line 6: Value range for moxalactam, presently " $0.3-1.0$," should read “0.03-1.0."

\section{Tentative Interpretive Criteria for the Diffusion Susceptibility Test Using 30- $\mu$ g Netilmicin Disks}

RONALD N. JONES, ARTHUR L. BARRY, AND CLYDE THORNSBERRY

Department of Pathology, Kaiser Foundation Laboratory (Oregon Region), Clackamas, Oregon 97015; Clinical Microbiology Laboratory, University of California Davis Medical Center, Sacramento, California 95817; and Antimicrobics Investigations Section, Center for Disease Control, Atlanta, Georgia 30333

Vol. 18, no. 3, p. 489, Table 2, footnote $b$ : “ $(P<0.5$, $>0.02)$ " should read (" $P<0.05,>0.02)$." 